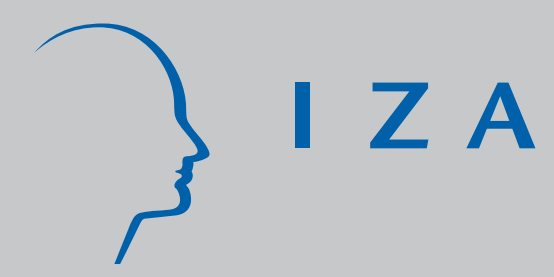

IZA DP No. 2950

Informality as a Stepping Stone:

Entrepreneurial Entry in a Developing Economy

J ohn Bennett

Saul Estrin

July 2007 


\title{
Informality as a Stepping Stone: Entrepreneurial Entry in a Developing Economy
}

\author{
John Bennett \\ Brunel University \\ and IZA \\ Saul Estrin \\ London School of Economics \\ and IZA
}

Discussion Paper No. 2950

July 2007

IZA

P.O. Box 7240

53072 Bonn

Germany

Phone: +49-228-3894-0

Fax: +49-228-3894-180

E-mail: iza@iza.org

\begin{abstract}
Any opinions expressed here are those of the author(s) and not those of the institute. Research disseminated by IZA may include views on policy, but the institute itself takes no institutional policy positions.

The Institute for the Study of Labor (IZA) in Bonn is a local and virtual international research center and a place of communication between science, politics and business. IZA is an independent nonprofit company supported by Deutsche Post World Net. The center is associated with the University of Bonn and offers a stimulating research environment through its research networks, research support, and visitors and doctoral programs. IZA engages in (i) original and internationally competitive research in all fields of labor economics, (ii) development of policy concepts, and (iii) dissemination of research results and concepts to the interested public.
\end{abstract}

IZA Discussion Papers often represent preliminary work and are circulated to encourage discussion. Citation of such a paper should account for its provisional character. A revised version may be available directly from the author. 
IZA Discussion Paper No. 2950

July 2007

\section{ABSTRACT}

\section{Informality as a Stepping Stone: Entrepreneurial Entry in a Developing Economy*}

We model decisions with respect to formality or informality for entrepreneurs in a new industry for a developing economy. We show that informality allows a leader to explore, without significant sunk costs, the potential profitability of the industry; that is, informality may be a stepping stone, enabling an entrepreneur to experiment cheaply in an uncertain environment. There are circumstances under which, without this option, the industry would not become established. We analyse the roles of parameters such as a minimum wage rate and we show that the existence of finance constraints can actually encourage entry in this context.

JEL Classification: O17, L10

Keywords: informal sector, entry, developing economy

Corresponding author:

John Bennett

Centre for Economic Development and Institutions (CEDI)

Brunel University

Uxbridge, UB8 3PH

United Kingdom

E-mail: john.bennett@brunel.ac.uk

\footnotetext{
* Earlier versions of this paper were presented at the International Labor Conference, University of Michigan, May, 2007, and the IZA/World Bank Conference on Employment and Development, Bonn, June, 2007. We are grateful to the participants for very helpful comments.
} 


\section{Informality as a Stepping Stone: Entrepreneurial Entry in a Developing Economy}

\section{Introduction}

In this paper we model the process of entrepreneurial entry by new firms, both formal and informal, in a developing economy. Building on characterizations of the entry process and the distinction between formal and informal status, we establish the conditions under which entry and survival of either type takes place when a new opportunity becomes available for exploitation. We analyze whether an innovating firm (the 'leader') will initially be formal or informal; how the leader may adapt (into or out of formality) once profitability becomes known; and the choice between formality and informality for a second firm (the 'follower'). We also consider how finance constraints may affect the pattern of entry.

There is already a large literature on the choice between formal and informal status in a developing economy. Lewis (1954) formulated a two-sector model of developing economies in which a reservoir of surplus labor was reduced as the high-productivity sector grew to absorb it. The Harris-Todaro model (1970) formalized this view of segmented labor markets in developing countries in a tradition that has been surveyed and extended by numerous authors including Chandra and 
Khan (1993), Loayza (1994) and Fields (2005). Papers in this tradition tend to view the informal sector as passive, supplying labor to the formal sector at a relatively low fixed wage. There is a second strand in the literature, originating in the ILO Report on Kenya (1972) that suggests that, far from disappearing, the informal sector could instead provide a basis for employment creation and growth. ${ }^{1}$ Maloney has taken this approach further, drawing primarily on Latin American experience to argue that the informal sector is probably better viewed as entrepreneurial (see for example Maloney, 1999, 2004). To quote Maloney (2004, p.1), 'as a first approximation we should think of the informal sector as the unregulated developing country analogue of the voluntary entrepreneurial small firm sector found in developing countries'. Our paper follows this lead in the specific context of entrepreneurial entry.

A number of papers have sought to model the interaction between the formal and informal sectors, treating their relative size as endogenous, commencing with Rauch (1991). In his approach, a firm is defined to be formal at or above a certain size, in which case it must meet a minimum wage constraint. It is shown that the relative size of firms in the two sectors, and therefore the scale of the informal sector, will be sensitive to the gap between the minimum and the marketclearing wage. We follow Rauch's model in allowing a choice between formal and informal status, and in exploring the role of the minimum wage in the choice

\footnotetext{
${ }^{1}$ This view is confirmed for Kenya more recently by Bigsten, Kimyu and Lundvall (2004).
} 
of formality/informality status. ${ }^{2}$ De Paula and Scheinkman (2006) also study the determinants of informal sector activity, defining informality in terms of tax avoidance. They deduce that informal sector firms will be smaller and have a higher cost of capital, results supported by their empirical work on Brazil. Our framework draws on their results with respect to firm size.

Our approach differs from the literature in its focus on de novo entry, allowing us to concentrate on the choice of formal versus informal status when the industry, as well as the firm, is being created by the entry process. ${ }^{3}$ We follow Hausmann and Rodrik (2003) in arguing that, while innovation in developing countries will typically be through the imitation of existing production methods in developed economies, such technology is not common knowledge. Rather, the transfer of technology to new economic and institutional environments requires adaptations, and there is an associated uncertainty about the future profitability of the new ventures in a developing economy (see also Hausmann, Hwang and Rodrik, 2006). Hence, we model entrepreneurs that set up firms in a 'new' industry, the profitability of which is initially unknown. The paper builds on the context formulated in

\footnotetext{
${ }^{2}$ Straub (2005) also models a firm's choice between the two legal statuses, but he assumes that, having forgone the cost of registration, formal sector firms can gain from participating in the formal credit market, while informal sector firms cannot. The balance of advantage between formality and informality depends on the costs of registration as against the efficiency of alternative credit mechanisms.

${ }^{3}$ Weak institutions, and in particular high levels of taxation and regulation burdening formal firms, combined with an inability to enforce property rights, including those of the state, have been regarded in the literature as the main cause of the emergence of the informal sector (see, e.g., Loayza, 1994). In this paper we take as given that institutions are weak and that informality, as well as formality, is an option for potential entrants.
} 
Bennett and Estrin (2006), though that paper considers only entry by formal firms. In the present paper the concern is with the choice of legal status (formal or informal) both at the point of entry, and subsequently, once the potential profitability of the industry is revealed. Thus, firms can enter formally or informally, and change their status in either direction once the profitability of the industry becomes known and entrepreneurs have re-evaluated their prospects in the light of this information. We follow Rauch (1991) and de Paula and Scheinkman (2006) in exploring the factors encouraging entry with informal or formal status, but our framework allows a wider variety of determinants to be investigated and also the interactions between the two sectors, including strategic behavior, to be analyzed. Thus, the distinctive feature of our analysis of formality/informality is its focus on entrepreneurial entry. By analyzing the choice of status from the time at which the industry is first set up in the developing economy, and providing a simple dynamic formulation, we are able to bring the roles of uncertainty and experimentation into the analysis. Such issues may be critical in the life cycle of an industry, but are excluded when a static approach is taken. Also, we are able to allow strategic behavior in the choice of formality/informality status, given that the acquisition of either status involves a sunk cost - which is higher in the case of formality.

To undertake such an analysis, we need to characterize the essential features of formal and informal sector firms in a parsimonious manner. In our model 
both the formal and informal sector pay a fixed wage per worker, but the formal sector labor cost includes an additional element which either can either represent the cost of supplying social benefits or, as in Rauch (1991), the minimum wage that must be paid to formal sector workers. As noted above, further distinguishing characteristics of informal sector firms in the model are their size and productivity. Following de Paula and Scheinkman (2006), we assume formal firms are larger and, in much of the analysis, more productive. For simplicity we model a fixedcoefficient technology, in which formal sector firms are not assumed to be more capital intensive. Their (likely) productivity advantage is instead captured in terms of higher output per worker (and capital).

In our model there only two periods and two entrepreneurs (i.e., potentially, there may be two firms in the industry). The model is solved by backward induction. In the second period the leader, firm A, is already an incumbent, and may be formal or informal (or it may exit). Depending on the realization of profitability and the values of other parameters, entry by the follower, firm B, may occur, either formally or informally, and we formulate the Nash equilibrium that obtains. In the first period the entrepreneur controlling firm A decides whether to enter, and, if so, whether firm A should be formal or informal. He or she takes into account the equilibrium that will obtain in period 2 for all possible realizations of profitability of the industry. 
Even in this simple formulation, the analysis is quite complex. However, our simplifying assumptions yield tractability with regard to the roles of factors such as the market (informal-sector) wage rate, minimum wages in the formal sector, and social benefits. Some results that we obtain would have been expected intuitively, such as that a higher minimum wage in the formal sector is conducive to the growth of the informal rather than the formal sector. Others might not have been predicted. For example, in terms of comparative statics, a higher realized productivity may have a non-monotonic effect on the number of informal firms, and for intermediate realizations may lead to multiple equilibria and churning of both the number of firms and their status. Moreover, credit constraints can affect the balance of entry in a way that may be found surprising: credit constraints may stimulate informal entry even when they do not prevent formal entry.

In Section 2 we outline the model and our main assumptions. Because even this simple framework can generate many cases, in the subsequent sections we do not assume productivity differences between formal and informal sector firms and an upward sloping capital supply curve simultaneously. Rather, in Section 3 we consider the evolution of the industry with a perfectly elastic capital supply, but with the formal sector assumed to be more productive than the informal. Then in Section 4 we do the converse, analyzing the case of an upward-sloping capital supply curve on the assumption that productivity in the two sectors is the same. 
Section 5 concludes.

\section{The Set-Up}

We consider an innovation in a developing economy in the form of imitation of a technique that already exists in developed economies. The transfer of technology to the new economic and institutional environment requires adaptation, and there is an associated uncertainty about the future of profitability of the venture (see Hausmann and Rodrik, 2003; Bennett and Estrin, 2006). When an entrepreneur sets up a firm in a particular 'new' industry, the profitability is initially unknown. We focus on a simple example, with two entrepreneurs, two time periods, fixed input proportions, and a constant price of output. ${ }^{4}$

In the industry that we analyze there are no incumbent firms at time $t=0$, but the leader, entrepreneur A, may innovate, setting up a firm (also called A) to enter the industry and produce at $t=1$. The firm may be either informal or formal at $t=1$. Its activity at $t=1$ reveals the profitability of the industry, which is then common knowledge. At $t=2$ entrepreneur A may then exit the industry, or keep the firm at its original formality/informality status, or switch status. We assume that the follower, entrepreneur $\mathrm{B}$, observes that $\mathrm{A}$ has entered at $t=1$ and then, when A's profitability is revealed, may enter at $t=2$, either formally

\footnotetext{
${ }^{4}$ In effect, we are making the small open economy assumption. Although price is fixed, the suitability of the industry to local conditions makes profitability unknown before entry occurs.
} 
or informally. Thus, there may be one or two firms in the industry at $t=2$, with both firms being formal, or both informal, or one formal and the other informal. There are no further time periods in the model.

We follow Rauch (1991) in using firm size, measured in terms of employment, as a defining characteristic of formality, an informal firm employing one unit of labor, while a formal firm employs two. Factor proportions are fixed: an informal firm requiring $k$ units of capital, and a formal firm $2 k$. If firm A enters informally at $t=1$ it purchases $k$ units of capital. If it switches to formality at $t=2$ it must purchase $k$. If it enters formally at $t=1$ and then switches to informality it disposes of its unused capital freely.

Rauch (1991) and Loayza (1994) regard the requirement to pay minimum wages as an essential characteristic of the formal sector. We model this by assuming that whereas the market wage $w$ is paid in the informal sector, the formal sector pays an increment $s$, where $w+s \equiv \bar{w}$ can be interpreted as the minimum wage. Alternatively, $s$ may be regarded as the cost of supplying social benefits to formal sector workers. We write $\bar{w}$ in place of $w+s$ where this is more consistent with the exposition.

To reflect shortage of capital, we assume that the unit price $r_{t}$ of capital at time $t$ may be increasing in $K_{t}$, the aggregate amount of capital bought at $t$ :

$$
r_{t}=1+\left[K_{t}-1\right] \rho, \text { where } \rho \geq 0 \text {. }
$$


Since capital is assumed to be bought in units of $k$, this implies that if $k$ units are bought the price is unity, if $2 k$ are bought the price per unit is $1+\rho$, and if $3 k$ are bought it is $1+2 \rho$. If $\rho=0$ then $r_{t}=1$.

In addition to the social cost $s$, we characterize informality in terms of size. Being larger is a potential benefit to a firm: if the industry is profitable, the extra size associated with formality will enable it to earn further profits (whereas if the industry is not profitable, the firm is not obliged to be formal). We allow for one further difference: as noted by de Paula and Scheinkman (2006), and also Straub (2005), a formal firm may enjoy a productivity benefit $\beta$ : although it uses twice as many inputs as an informal firm does, its output is $2 \beta$ that of the informal firm, where $\beta \geq 1 .^{5}$

We assume that the profitability of the industry depends on the value taken by a stochastic term $\theta$, which may represent demand or cost factors. $\theta$ captures the idea that, although the industry may exist in other countries, its suitability to local conditions and institutions can only be discovered by experimentation. At $t=1, \theta$ is stochastic, being uniform over $[0,2 \Theta]$; but, given that entrepreneur A sets up his or her firm at $t=1$, either informally or formally, the value of $\theta$ is common knowledge at $t=2$. This represents the idea that the suitability of the industry to local conditions and institutions is discovered by experimentation.

\footnotetext{
${ }^{5}$ Formality may also enable the firm to sell output to the government, presumably at a price that is at least as high as that for private sales. The parameter $\beta$ may be interpreted as reflecting this differential.
} 
Apart from $\theta$ at $t=1$, everything in the model is common knowledge.

At $t=1$ firm A's respective profits if is informal and if it is formal are

$$
\begin{aligned}
\pi_{1 i}^{A} & =\theta-w-k \\
\pi_{1 f}^{A} & =2[\beta \theta-w-s-(1+\rho) k] .
\end{aligned}
$$

At $t=2$, if $\mathrm{A}$ is informal it does not have to purchase any capital, regardless of the status it chose at $t=1$, and so its profit is

$$
\pi_{2 i}^{A}=\theta-w
$$

If, however, $\mathrm{A}$ is formal at $t=2$ its profit depends on its status at $t=1$, because a switch from informality to formality involves the purchase of an extra unit of capital. Its profit also depends, through the price of capital, on the behavior of firm $\mathrm{B}$ at $t=2$. Thus, A's profit at $t=2$ is

$$
\begin{aligned}
\pi_{2 f}^{A} & =2(\beta \theta-w-s)-r_{2} k \text { if } \mathrm{A} \text { informal at } t=1 \\
& =2(\beta \theta-w-s) \text { if } \mathrm{A} \text { formal at } t=1
\end{aligned}
$$


At $t=2$ firm B's profit is

$$
\begin{aligned}
& \pi_{2 i}^{B}=\theta-w-r_{2} k \text { if B informal; } \\
& \pi_{2 f}^{B}=2\left[\beta \theta-w-s-r_{2} k\right] \text { if B informal. }
\end{aligned}
$$

We assume that at $t=1$ firm A makes decisions so as to maximize the expected present value of its profit stream, applying a discount factor $\sigma \in(0,1]$. At $t=2$ both $\mathrm{A}$ and $\mathrm{B}$ independently maximize profits. We solve the model by backward induction. We begin by considering $t=2$, first on the assumption that A entered formally at $t=1$, and then assuming that A entered informally at $t=1$. In each of these two cases we consider the behavior of A and B for all possible realizations of $\theta$. For each such realization A must choose between exit, informality, and formality, while B must choose between staying out, informality and formality; and we determine the Nash equilibrium in each case. Then we consider $t=1$. Here, taking into account all the potential outcomes at $t=2$, A must decide whether to enter, and, if so, whether to take informal or formal status.

Even this simple framework would generate a large number of different cases, and so we simplify our analysis as follows. First, we include the productivity benefit of formality, i.e., we assume that $\beta>1$; but we assume that the price of capital is fixed, i.e., that $\rho=0$, so that $r_{t}=1$. Then we change each of these assumptions: we assume that there is no productivity benefit $(\beta=1)$ but that the 
supply curve of capital is upward-sloping $(\rho>0)$. In this case the profit of each firm depends on the behavior of the other and so there is strategic interaction. In describing the firms' choices at $t=2$ we use $\mathrm{X}$ to indicate exit, I informal status, F formal status and SO staying out of the industry.

\section{Formality gives a Productivity Advantage}

In this section we assume that $\beta>1$ but $\rho=0$. We begin by considering $t=2$, first on the assumption that the leader, firm A, entered formally at $t=1$, and then on the assumption that it entered informally at $t=1$. A comparison follows.

\subsection{Behavior at $t=2$ when Firm A Formal at $t=1$}

If $\mathrm{A}$ entered formally at $t=1$ it will not acquire additional capital at $t=2$. Neither firm's behavior at $t=2$ affects the profit of the other, so that for each possible realization of $\theta$ we have a dominant-strategy equilibrium. If it stays in production, firm A's profits at $t=2$ are given by (2) or (4); that is, they are $\theta-w$ if it chooses I, but $2(\beta \theta-w-s)$ if it chooses F. Assuming firm B enters, B's profits at $t=2$ are given by (5) or (6); that is, they are $\theta-w-k$ if it chooses I, but $2(\beta \theta-w-s-k)$ if it chooses $\mathrm{F}$.

The unit cost of output with formality, relative to that under informality, is raised by the existence of the social cost $s$, but lowered by the productivity benefit 
$\beta$. Given that $\mathrm{A}$ acquired $k$ units of capital at $t=1$, its unit cost of output at $t=2$ is $w$ if it chooses I, but $(w+s) / \beta$ if it chooses F. If $w \geq(w+s) / \beta$, A does not choose I for any realization of $\theta$ at $t=2$, whereas if $w<(w+s) / \beta$ A may choose either I or F, depending on the realization of $\theta$. Even if the unit cost is greater for formality, the higher output that formality allows may make it more profitable than informality.

Hence, comparing firm A's profit levels across its options at $t=2$, and rewriting the unit cost inequality, it is found that if

$$
s \leq(\beta-1) w,
$$

I is never chosen - A chooses either $\mathrm{X}$ or F. Then A's dominant strategy is $\mathrm{X}$ if $\theta<(w+s) / \beta$, but $\mathrm{F}$ if $\theta \geq(w+s) / \beta$. If, however, (7) does not hold, i.e., if $(\beta-1) w<s$, A may, depending on the realization $\theta$, choose any of the three options, X, I, or F. A's dominant strategy is then $\mathrm{X}$ if $\theta<w$; I if $w \leq \theta<$ $(w+2 s) /(2 \beta-1)$; but $\mathrm{F}$ if $(w+2 s) /(2 \beta-1) \leq \theta \leq 2 \Theta$.

Similar considerations apply to firm $\mathrm{B}$ at $t=2$, but taking into account that B, as follower, must still acquire capital to produce. Its unit cost of output is $w+k$ if it chooses I, but $(w+s+k) / \beta$ if it chooses $\mathrm{F}$. Thus, if

$$
s \leq(\beta-1)(w+k)
$$


B does not choose I, irrespective of the realization of $\theta$. If (8) holds, B's dominant strategy is $\mathrm{SO}$ if $\theta<(w+s+k) / \beta$, but $\mathrm{F}$ if $\theta \geq(w+s+k) / \beta$. If, however, $s>(\beta-1)(w+k)$, B's dominant strategy is SO if $0<\theta<w+k$; I if $w+k \leq$ $\theta<(w+k+2 s) /(2 \beta-1)$; and $\mathrm{F}$ if $[w+k+2 s] /(2 \beta-1) \leq \theta \leq 2 \Theta$.

Given that (7) and (8) each may or may not hold, there are three alternative cases:

(a) $s \leq(\beta-1) w<(\beta-1)(w+k)$. In this case neither firm will choose to be informal at $t=2$. If $0 \leq \theta<(w+s) / \beta$, the firms choose $\{\mathrm{X}, \mathrm{SO}\}$, where the two terms in $\{$.$\} are A's and B's respective choices. If (w+s) / \beta \leq \theta<(w+s+k) / \beta$, the firms choose $\{\mathrm{F}, \mathrm{SO}\}$. If $(w+s+k) / \beta \leq \theta \leq 2 \Theta$, they choose $\{\mathrm{F}, \mathrm{F}\}$. Given A's profits at $t=2$ for each range of realization of $\theta$, we obtain its expected profit $E \pi_{2}^{A}(f)$ at $t=2$, given that it enters formally at $t=1$ (with the expectation being taken at the beginning of $t=1)$ :

$$
2 \Theta E \pi_{2}^{A}(f)=\int_{(w+s) / \beta}^{2 \Theta} 2(\beta \theta-w-s) d \theta=\frac{1}{\beta}(w+s)^{2}+4 \Theta[\beta \Theta-(w+s)]
$$

The limits on the integral here define the range of $\theta$ values for which $\mathrm{F}$ is chosen by $\mathrm{A}$ at $t=2$, and $2(\beta \theta-w-s)$ is the profit earned for each realization of $\theta$ in 
this range. For (9) to be valid, we assume

$$
2 \Theta>(w+s) / \beta
$$

By assuming that $\Theta$ is this large, we ensure that in the equilibrium at $t=2$ the outcome $\{\mathrm{F}, \mathrm{F}\}$ is a possibility. If we restricted $\Theta$ to taking a lower value, then $\{\mathrm{F}, \mathrm{F}\}$, and perhaps other outcomes, would be ruled out by assumption. A similar assumption to (10) is made below for each of our other cases.

(b) $(\beta-1) w<s \leq(\beta-1)(w+k)$. Under these conditions A may choose informality at $t=2$, but $\mathrm{B}$ will not. The following choices then obtain. If $0 \leq$ $\theta<w$, we have $\{\mathrm{X}, \mathrm{SO}\}$; if $w \leq \theta<(w+2 s) /(2 \beta-1)$, we have $\{\mathrm{I}, \mathrm{SO}\} ;^{6}$ if $(w+2 s) /(2 \beta-1) \leq \theta<(w+s+k) / \beta$, we have $\{\mathrm{F}, \mathrm{SO}\} ;$ and if $(w+s+k) / \beta \leq$ $\theta \leq 2 \Theta$, we have $\{F, F\}$. Thus, in case (b) we obtain

$$
\begin{aligned}
2 \Theta E \pi_{2}^{A}(f) & =\int_{w}^{(w+2 s) /(2 \beta-1)}(\theta-w) d \theta+\int_{(w+2 s) /(2 \beta-1)}^{2 \Theta} 2(\beta \theta-w-s) d \theta \\
& =\frac{1}{2} \frac{(w+s)^{2}}{(2 \beta-1)}+\frac{1}{2} w^{2}+4 \Theta[\beta \Theta-(w+s)] .
\end{aligned}
$$

The first integral relates to the range of $\theta$ for which $\mathrm{I}$ is chosen by A, and the

\footnotetext{
${ }^{6}$ Since $s \leq(\beta-1)(w+k)$ by assumption in case $(\mathrm{b})$, it is found that $(w+2 s) /(2 \beta-1)<$ $(w+s+k) / \beta$. Thus, the range $\theta \in[w,(w+2 s) /(2 \beta-1))$ does not overlap with the range $\theta \in[(w+2 s) /(2 \beta-1),(w+s+k) / \beta)$.
} 
second for which $\mathrm{F}$ is chosen by A. For (11) to be valid, we assume

$$
2 \Theta>(w+2 s) /(2 \beta-1) .
$$

(c) $(\beta-1) w<(\beta-1)(w+k)<s$. In this case $s$ is relatively large, so that each firm may choose I at $t=2$. There are two subcases here, depending on the relative sizes of $(w+2 s) /(2 \beta-1)$ and $w+k$. Suppose first that $(w+2 s) /(2 \beta-1)>w+k$. Then, if $0 \leq \theta<w$, we have $\{\mathrm{X}, \mathrm{SO}\}$; if $w \leq \theta<w+k$, we have $\{\mathrm{I}, \mathrm{SO}\}$; if $w+k \leq \theta<(w+2 s) /(2 \beta-1)$, we have $\{\mathrm{I}, \mathrm{I}\} ;$ if $(w+2 s) /(2 \beta-1) \leq \theta<$ $(w+s+k) /(2 \beta-1)$, we have $\{\mathrm{F}, \mathrm{I}\}$; and if $(w+s+k) /(2 \beta-1) \leq \theta \leq 2 \Theta$, we have $\{\mathrm{F}, \mathrm{F}\}$. If, alternatively, $(w+2 s) /(2 \beta-1) \leq w+k$, the following obtains. If $0 \leq \theta<w$, we have $\{\mathrm{X}, \mathrm{SO}\}$; if $w \leq \theta<(w+2 s) /(2 \beta-1)$, we have $\{\mathrm{I}, \mathrm{SO}\}$; if $(w+2 s) /(2 \beta-1) \leq \theta<w+k$, we have $\{\mathrm{F}, \mathrm{SO}\}$; if $w+k \leq \theta<(w+s+k) /(2 \beta-1)$, we have $\{\mathrm{F}, \mathrm{I}\}$; and if $(w+s+k) /(2 \beta-1) \leq \theta \leq 2 \Theta$, we have $\{\mathrm{F}, \mathrm{F}\}$. For case (c) it is found that again (11) holds.

Within each case, (a), (b) and (c), $E \pi_{2 f}^{A}$ is increasing in $\Theta$ and $\beta$, and decreasing in $w$ and $s$; and it is independent of $k$.

\subsection{Behavior at $t=2$ when Firm A Informal at $t=1$}

Assuming now that the leader, firm A, entered informally at $t=1$, the profit levels at $t=2$ of each firm are the same as when $\mathrm{A}$ enters formally at $t=1$, except in 
one respect: if $\mathrm{A}$ chooses $\mathrm{F}$ at $t=2$ it must then spend $k$ to expand its capital stock (its profit then is $2(\beta \theta-w-s)-k$, as given by (3) with $r_{2}=1$ ).

Comparing firm A's profits across its three options, it is found that if

$$
s+\frac{k}{2} \leq(\beta-1) w
$$

it does not choose I at $t=2$ for any realization of $\theta$. The term $k / 2$ appears in (12) but not in (7) because the of the additional expenditure $k$ that is required to obtain the output associated with F. If (12) holds, A's dominant strategy is X if $\theta<\left(w+s+\frac{k}{2}\right) / \beta$, but $\mathrm{F}$ if $\theta \geq\left(w+s+\frac{k}{2}\right) / \beta$

If, however, (12) does not hold, i.e., if $s+\frac{k}{2}>(\beta-1) w$, A's dominant strategy is $\mathrm{X}$ if $\theta<w$; I if $w \leq \theta<(w+2 s+k) /(2 \beta-1)$; but $\mathrm{F}$ if $(w+2 s+k) /(2 \beta-1) \leq \theta$.

The factors affecting firm B's choices are the same as in the previous section (i.e., when A entered formally at $t=1$ ). Putting A's and B's choices together, three cases may again be distinguished, for which similar considerations apply as in cases (a)-(c):

(d) $s+\frac{k}{2} \leq(\beta-1) w<(\beta-1)(w+k)$. If $0 \leq \theta<\left(w+s+\frac{k}{2}\right) / \beta$, the firms choose $\{\mathrm{X}$,SO $\}$. If $\left(w+s+\frac{k}{2}\right) / \beta \leq \theta<(w+s+k) / \beta$, they choose $\{\mathrm{F}$,SO $\}$. If $(w+s+k) / \beta \leq \theta \leq 2 \Theta$, they choose $\{\mathrm{F}, \mathrm{F}\}$. For this case, A's expected profit 
$E \pi_{2 i}^{A}$ at $t=2$ when it enters informally at $t=1$, is given by

$$
\begin{aligned}
2 \Theta E \pi_{2}^{A}(i)= & \int_{\left(w+s+\frac{k}{2}\right) / \beta}^{(w+s+k) / \beta}(\theta-w) d \theta+\int_{(w+s+k) / \beta}^{2 \Theta}[2(\beta \theta-w-s)-k] d \theta \\
= & 2 \Theta[2 \beta \Theta-2(w+s)-k]+\frac{k}{2 \beta^{2}}\left[s+\frac{3}{4} k-(\beta-1) w\right] \\
& +\frac{1}{\beta}(w+s+k)(w+s)
\end{aligned}
$$

For (13) to be valid, we assume

$$
2 \Theta>(w+s+k) / \beta \text {. }
$$

(e) $(\beta-1) w<s+\frac{k}{2} \leq(\beta-1)(w+k)$. In this case $(w+2 s+k) /(2 \beta-1)<$ $(w+s+k) / \beta$. Thus, if $0 \leq \theta<w$, we have $\{\mathrm{X}, \mathrm{SO}\}$; if $w \leq \theta<(w+2 s+k) /(2 \beta-1)$, we have $\{\mathrm{I}, \mathrm{SO}\}$; if $(w+2 s+k) /(2 \beta-1) \leq \theta<(w+s+k) / \beta$, we have $\{\mathrm{F}, \mathrm{SO}\}$; and if $(w+s+k) / \beta \leq \theta \leq 2 \Theta$, we have $\{\mathrm{F}, \mathrm{F}\}$. This yields

$$
\begin{aligned}
2 \Theta E \pi_{2}^{A}(i) & =\int_{w}^{(w+2 s+k) /(2 \beta-1)}(\theta-w) d \theta+\int_{(w+2 s+k) /(2 \beta-1)}^{2 \Theta}[2(\beta \theta-w-s)-k] d \theta \\
& =2 \Theta[2 \beta \Theta-2(w+s)-k]+\frac{1}{2} w^{2}+\frac{1}{2(2 \beta-1)}(w+2 s+k)^{2}
\end{aligned}
$$

For (14) to be valid, we assume

$$
2 \Theta>(w+2 s+k) /(2 \beta-1) .
$$


(f) $(\beta-1) w<(\beta-1)(w+k)<s+\frac{k}{2}$. If $0 \leq \theta<w$, we have $\{\mathrm{X}, \mathrm{SO}\}$. If $w \leq \theta<w+k$, we have $\{$ I,SO $\}$. If $w+k \leq \theta<(w+2 s+k) /(2 \beta-1)$, we have $\{\mathrm{I}, \mathrm{I}\}$. If $(w+2 s+k) /(2 \beta-1) \leq 2 \Theta$, we have $\{\mathrm{F}, \mathrm{F}\}$. In this case (14) again holds.

As in cases (a)-(c), within each case (d), (e) and (f), $E \pi_{2 f}^{A}$ is increasing in $\Theta$ and $\beta$, and decreasing in $w$ and $s$; it is independent of $k$.

\subsection{A's Choice of Status at $t=1$}

We assume that A's objective at the beginning of $t=1$ is to maximize the present value of its expected profit stream. If A enters formally at $t=1$ this present value is

$$
E V^{A}(f)=2(\beta \Theta-w-s-k)+\sigma E \pi_{2}^{A}(f)
$$

where $\sigma \in(0,1]$ is a discount factor. If $\mathrm{A}$ enters informally at $t=1$ the present value is

$$
E V^{A}(i)=\Theta-w-k+\sigma E \pi_{2}^{A}(i)
$$

Given that A enters, it prefers formality (informality) if

$$
E V^{A}(f)-E V^{A}(i)=\Delta_{1}+\sigma \Delta_{2}>(<) 0,
$$


where

$$
\begin{aligned}
& \Delta_{1}=(2 \beta-1) \Theta-w-2 s-k>0 ; \\
& \Delta_{2}=E \pi_{2}^{A}(f)-E \pi_{2}^{A}(i) .
\end{aligned}
$$

$\Delta_{1}$ is the net gain in terms of expected $t=1$ profit from choosing formality rather than informality at $t=1 ; \Delta_{2}$ is the net gain in terms of expected $t=2$ profit from choosing formality rather than informality at $t=1$. From (16),

$$
\Delta_{1} \gtreqless 0 \text { as } \Theta \gtreqless(w+k+2 s) /(2 \beta-1) .
$$

However, under the present assumptions $\Delta_{2}$ is found to be positive in all cases because formal entry at $t=1$ involves the purchase of more capital than informal entry at $t=1$ does. This additional capital may then be used profitably at $t=2$, and it is assumed that there are no costs of disposal if it is not used. There are three combinations of cases (a)-(c) and (d)-(f) that are mutually consistent.

I. Low Social Costs: $s<s+\frac{k}{2} \leq(\beta-1) w$. This combination of parameter values, which can also be interpreted as a relatively low minimum wage $(\bar{w}+k / 2<$ $\beta w)$ obtains when cases (a) and (d) hold together. Neither firm will choose to be informal at $t=2$, regardless of the formality/informality status of firm A at $t=1$. 
From (9) and (13),

$$
\Delta_{2}=k-\frac{k}{4 \beta^{2} \Theta}\left[(1+2 \beta) s+(1+\beta) w+\frac{3}{4} k\right] .
$$

II. Intermediate Social Costs: $s \leq(\beta-1) w<s+\frac{k}{2}$. This combination can be interpreted as representing an intermediate value of the minimum wage $(\bar{w} \leq \beta w<\bar{w}+k / 2)$, obtains when (a) holds with either (e) or (f). If A enters formally at $t=1$ neither firm will choose informality at $t=2$; but if $\mathrm{A}$ enters informally at $t=1$ either firm may choose any status at $t=2$. In case (e) firm B will not choose informality for any realization of $\theta$; but in case (f) it will choose informality for some $\theta$. From (9) and (14),

$$
\Delta_{2}=k-\frac{1}{4 \beta(2 \beta-1) \Theta}\left\{2[(\beta-1) w-s]^{2}+\beta k(k+4 s+2 w)\right\}
$$

III. High Social Costs: $(\beta-1) w<s<s+k / 2$. These inequalities, which represent a high minimum wage $(\beta w<\bar{w})$ obtain when any of three combinations hold: (b) with (e), (b) with (f), or (c) with (f). Here, any combination of formality or informality for the two firms may obtain at $t=2$. From (11) and (14),

$$
\Delta_{2}=k-\frac{1}{4(2 \beta-1) \Theta}(s+k)(2 w+3 s+k) .
$$

For each of I, II, and III, the following obtain. Since $\Delta_{2}>0$, we have from 
(17) that a sufficient condition for formal entry at $t=1$ to be preferred overall is that

$$
\Theta \geq(w+k+2 s) /(2 \beta-1)
$$

Using (15), we find that $d\left[E V^{A}(f)-E V^{A}(i)\right] / d \Theta>0$; i.e., a higher $\Theta$ favors formality at $t=1$. Also, $E V^{A}(f)-E V^{A}(i)$ is increasing in $\beta$ and $\sigma$, and decreasing in $w, s$ and $k$. There is a critical value of $\Theta$, which we denote by $\bar{\Theta}$, at which $E V^{A}(f)-E V^{A}(i)=0$. We write $\bar{\Theta}=\bar{\Theta}^{I}$ for low, $\bar{\Theta}=\bar{\Theta}^{I I}$ for medium, and $\bar{\Theta}=\bar{\Theta}^{I I I}$ for high social costs. Thus we obtain ${ }^{7}$

$$
\bar{\Theta}^{I}<\bar{\Theta}^{I I}<\bar{\Theta}^{I I I}
$$

The minimum value of $\Theta$ for which A will choose formality at $t=1$ is greatest in the high social cost case and smallest in the low social cost case. Holding $w$ constant, an increase in the minimum wage rate $\bar{w}$ reduces the relative attractiveness of formality for A at $t=1$ and increases $\bar{\Theta}$.

The first lemma summarizes some of these conclusions. For brevity, we describe formality as higher status than informality, and informality as higher status than staying out or exit.

\footnotetext{
${ }^{7}$ Taking the root of each relevant quadratic, and writing $w+2 s+(1-\sigma) k \equiv$ $\gamma$, we find $\bar{\Theta}^{I}=\frac{1}{2(2 \beta-1)}\left(\gamma+\left\{\gamma^{2}+\frac{\sigma k(2 \beta-1)}{\beta^{2}}\left[(1+2 \beta) s+(1+\beta) w+\frac{3}{4} k\right]\right\}^{1 / 2}\right) ; \quad \bar{\Theta}^{I I}=$ $\frac{1}{2(2 \beta-1)}\left(\gamma+\left\{\gamma^{2}+\frac{\sigma}{\beta}\left[2\{(\beta-1) w-s\}^{2}+\beta k(k+4 s+2 w)\right]\right\}^{1 / 2}\right) ; \quad \bar{\Theta}^{I I I}=\frac{1}{2(2 \beta-1)}\left(\gamma+\left\{\gamma^{2}+\right.\right.$ $\left.\left.\frac{\sigma}{\beta}\left[2\{(\beta-1) w-s\}^{2}+\beta k(k+4 s+2 w)\right]\right\}^{1 / 2}\right)$.
} 
Lemma 1 Suppose that $\beta>1$ and $\rho=0$. At $t=2$ the leader, firm $A$, never chooses a lower formality status than the follower, firm B. If $s \leq(\beta-1) w$, neither firm will choose informality at $t=2$, while if $(\beta-1) w<s$ informality may be preferred for $A$ at $t=1$ and for one or both of the firms at $t=2$. A sufficient condition for $A$ to prefer formal entry at $t=1$ is that $\Theta \geq(w+k+2 s) /(2 \beta-1)$.

We have seen that if $s \leq(\beta-1) w$, the social cost (or excess of the minimum wage over the market wage) $s$ being small, firm B will never choose informality - it either enters formally or stays out - but firm A may nonetheless choose informality for its entry at $t=1$. This is because informal entry allows $\mathrm{A}$, as leader, to explore the profitability of the industry without sinking a large investment. Given that there is no strategic interaction at $t=2$, there is no competitive disadvantage to making this choice. The potential disadvantage, however, is that if the realization of $\theta$ is relatively high then $\mathrm{A}$ will have forgone potential profits at $t=1$.

Note that for various ranges of parameter values the option of informality is taken up, whereas the entrepreneur concerned would not be willing to operate formally. Having the option of informality raises the expected present value of the profit stream of the entrepreneur concerned. It is not just that, depending on the realization of $\theta$, B may enter informally at $t=2$, but would not enter formally. It is also that, for a range of parameter values, the existence of the informal option at $t=2$, by raising the expected present value of A's profit stream above zero, can 
cause A to enter at $t=1$. Indeed, the existence of the informal option at $t=2$ may cause A to enter formally at $t=1$. The existence of the informal option at $t=1$ may be the critical factor that enables $\mathrm{A}$ to enter and then, for the relevant range of realizations of $\theta$, to become formal at $t=2$.

Proposition 1 Informality may be a stepping stone or a consolation prize.

In Table 1 we show the configurations of firm status that may obtain at $t=2$. With the combination of parameter values shown under column 1, for example, we see that as $\theta$ increases in value, firms $\mathrm{A}$ and $\mathrm{B}$ at first exit and stay out, respectively; then A becomes formal, while B stays out; and finally both firms become formal. Other columns are interpreted similarly. ${ }^{8}$

\begin{tabular}{|c|c|c|c|c|c|c|c|c|c|}
\hline \multicolumn{2}{|c|}{1} & \multicolumn{2}{|c|}{2} & \multicolumn{2}{c|}{3} & \multicolumn{2}{c|}{4} & \multicolumn{2}{c|}{5} \\
\hline X & SO & X & SO & X & SO & X & SO & X & SO \\
\hline F & SO & I & SO & I & SO & I & SO & I & SO \\
\hline F & F & F & SO & F & SO & I & I & I & I \\
\hline & & F & F & F & I & F & I & F & F \\
\cline { 3 - 10 } & & & F & F & F & F & & \\
\hline
\end{tabular}

Columns 1 and 2 can obtain for either formal or informal entry by firm A at

\footnotetext{
${ }^{8}$ Column 1 relates to cases (a) and (d); column 2 to (b) and (e); column 3 to (c) with $(w+2 s) /(2 \beta-1)>w+k ;$ column 4 to $(\mathrm{c})$ with $(w+2 s) /(2 \beta-1) \leq w+k ;$ and column 5 to (f). Any given row of the table does not in general correspond to the same range of $\theta$ across the columns.
} 
$t=1$. Columns 3 and 4 can only obtain if A entered formally at $t=1$. Column 5 can only obtain if A entered informally at $t=1$. Only in columns 4 and 5 do we find that both firms end up being informal, which happens for an intermediate value of $\theta$. Elsewhere in the table we find that, at most, only one firm is informal. This can be firm A, in which case B stays out, or it can be B, in which case A is formal. It is never found that B is formal while A is informal. This is because A has a strategic advantage as leader, having sunk capital costs before the follower, firm B, has been able to respond, so if there is to be mixed status in the industry it will be A that will be the firm operating with the larger capital stock.

Also, note that in three columns $(2,4$, and 5$)$ as $\theta$ gets larger - this can be interpreted as realized demand becoming greater - the number of informal firms in the industry rises then falls. This is because, as demand rises from a low level, informality can become more attractive than doing nothing, but as demand rises to a high level informality is rejected in favor of formality. However, in column 3 , as demand rises we at first get one informal firm (firm A); then as demand rises further, A prefers formality, though B still stays out so there are no informal firms. But when demand is higher still we get an informal firm again - firm B - while A is again formal.

Lemma 2 Suppose that $\beta>1$ and $\rho=0$. Then, as the realized profitability of the industry rises, the response in terms of the number of informal firms is not 
monotonic and may not be single-peaked.

Finally, we focus on some comparative statics. Using (18), if, for example, we interpret the shift from I to II to III as an increase in $s$, we can put this together with our results that $d \bar{\Theta}^{I} / d s, d \bar{\Theta}^{I I} / d s$ and $d \bar{\Theta}^{I I I} / d s$ are each positive to obtain a comparative statics result that spans all combinations of parameter values (see the next lemma). If we interpret parameter ranges in terms of the minimum wage $\bar{w}=s+w$, we can consider the effect of varying $w$ with $\bar{w}$ held constant. Making the alternative interpretation of the parameter ranges, we see that in this case as $w$ increases we move from III to II to I - that is, in the opposite direction to the increase in $s$ we have examined. If the informal wage increases, with the formal wage held constant, we move to parameter ranges where informality is less attractive. And within each of the three parameter ranges it is found that a higher level of the informal wage rate $w$ is associated with a lower value of $\bar{\Theta}$. We therefore obtain the following lemma.

Lemma 3 Suppose that $\beta>1$ and $\rho=0$. Then, with held $w$ constant, an increase in the minimum wage rate $\bar{w}$ reduces the relative attractiveness of formality for $A$ at $t=1$ and increases the value of $\Theta$ that is necessary for $A$ to choose formality at $t=1$. With $\bar{w}$ held constant, an increase in the informal wage rate $w$ has the opposite effects

It is also worth stressing, however, that the wedge $s$ between $w$ and $\bar{w}$ can 
actually enhance the role of informality. Suppose, in particular, that $s$ is reduced to zero (e.g., the minimum wage law is repealed). This increases the profits from formal operation both at $t=1$ and $t=2$. However, it also increases the present value of the expected profit stream for firm $\mathrm{A}$ if it enters informally at $t=1$ because A may switch to formality at $t=2$, and the profits from formality have been raised. Put differently, the existence of $s$ reduces the benefits that experimentation will produce if $\theta$ turns out favorably. While its removal favors formality relative to informality at $t=1$, it also favors informal entry relative to no entry at $t=1$. For some parameter values (ones for which formality at $t=1$ is not chosen), a minimum wage law that binds only on the formal sector may be the decisive factor that prevents entrepreneur A from entering informally, and thereby it prevents the industry from starting. Removal of the minimum wage law can thus enhance the role of informality as a stepping stone.

\section{Increasing Supply Price of Capital}

We now assume that $\rho>0$, whereas $\beta=1$. This has a significant effect on the analysis in that there is a now mutual dependence between A's and B's profits at $t=2$, and so there can be strategic interaction. The general nature of the results that we have obtained so far survives, but two main additional considerations enter the picture. One is that firms do not always have dominant strategies, and for a 
given realization of $\theta$ there may not be a unique pure-strategy Nash equilibrium. The other is that the introduction of an exogenous constraint can, because of strategic behavior by A, have interesting effects on the pattern of entry and status. Again we begin by considering $t=2$, first given that the leader, firm $\mathrm{A}$, entered formally and then given that it entered informally at $t=1$. A comparison follows.

\subsection{Behavior at $t=2$ when Firm A Formal at $t=1$}

Given that $\rho>0$, if A enters formally at $t=1$ it is found that at $t=2$ there is no range of parameter values for which informality is dominated for a firm for all possible realizations of $\theta$. Also, although any purchase of capital by B affects the price of capital, since A does not buy any capital (having already acquired $2 k$ at $t=2$ ) neither firm's behavior can affect the profits of the other. For each possible realization of $\theta$ we therefore have a dominant strategy equilibrium.

If $\mathrm{A}$ entered formally at $t=1$ it will not acquire additional capital at $t=2$. If it stays in production, its profits at $t=2$ are given by (2) or (4); that is, they are $\theta-w$ if it chooses I, but $2(\theta-w-s)$ if it chooses F. Assuming it enters, firm B's profits at $t=2$ are given by (5) with $r_{2}=1$ or (6) with $r_{2}=1+\rho$; that is, they are $\theta-w-k$ if it chooses I, but $2[\theta-w-s-(1+\rho) k]$ if it chooses $\mathrm{F}$.

A's dominant strategy is $\mathrm{X}$ if $0 \leq \theta<w$; I if $w \leq \theta<w+2 s$; and $\mathrm{F}$ if $w+2 s<\theta$. B's dominant strategy is SO if $0 \leq \theta<w+k$; I if $w+k \leq \theta<w+(1+2 \rho) k+2 s$; 
and $\mathrm{F}$ if $w+(1+2 \rho) k+2 s<\theta$. Together, these strategies imply that there are two cases:

(i) $k \geq 2 s$. In this case, if $0 \leq \theta<w$, we have $\{\mathrm{X}$,SO $\}$. If $w \leq \theta<w+2 s$, we have $\{\mathrm{I}, \mathrm{SO}\}$. If $w+2 s \leq \theta<w+k$, we have $\{\mathrm{F}, \mathrm{SO}\}$. If $w+k \leq \theta<$ $w+(1+2 \rho) k+2 s$, we have $\{\mathrm{F}, \mathrm{I}\}$. If $w+(1+2 \rho) k+2 s \leq \theta$, we have $\{\mathrm{F}, \mathrm{F}\}$.

(ii) $k<2 s$. In this case, if $0 \leq \theta<w$, we have $\{\mathrm{X}$,SO $\}$. If $w \leq \theta<w+k$, we have $\{\mathrm{I}, \mathrm{SO}\}$. If $w+k \leq \theta<w+2 s$, we have $\{\mathrm{I}, \mathrm{I}\}$. If $w+2 s \leq \theta<w+(1+2 \rho) k+2 s$, we have $\{\mathrm{F}$,I $\}$. If $w+(1+2 \rho) k+2 s \leq \theta$, we have $\{\mathrm{F}, \mathrm{F}\}$.

For both these cases, with firm A entering formally at $t=1$, its expected profit $E \pi_{2}^{A}(f)$ at $t=2$ is given by

$$
\begin{aligned}
2 \Theta E \pi_{2}^{A}(f) & =\int_{w}^{w+2 s}(\theta-w) d \theta+\int_{w+2 s}^{2 \Theta} 2(\theta-w-s) d \theta \\
& =2 s^{2}+w^{2}+2 s w+4 \Theta[\Theta-(w+s)]
\end{aligned}
$$

This is valid provided

$$
2 \Theta>w+2 s .
$$

Formal entry at $t=1$ yields $\mathrm{A}$ an expected profit stream with a present value of

$$
E V^{A}(f)=2[\Theta-w-s-(1+\rho) k]+\sigma E \pi_{2}^{A}(f) .
$$




\subsection{Behavior at $t=2$ when Firm A Informal at $t=1$}

If A enters informally at $t=1$ then, because each firm may choose to buy capital at $t=2$, and the supply price of capital is increasing, the profits of each firm depend on the behavior of the other firm. These profits, which are obtained from (2)-(6), using (1), are presented in Table 2, where firm A is represented in the rows and $\mathrm{B}$ in the columns. There is no range of parameter values for which informality is dominated for all possible realizations of $\theta$, and so, in the absence of dominant strategies, we examine the Nash equilibria for all realizations of $\theta$.

$\mathrm{B}$

\begin{tabular}{|c|c|c|c|c|}
\hline & & $\mathrm{SO}$ & $\mathrm{I}$ & $\mathrm{F}$ \\
\hline & $\mathrm{X}$ & 0 & 0 & 0 \\
\hline & & 0 & $\theta-w-k$ & $2[\theta-w-s-(1+\rho) k]$ \\
\hline A & I & $\theta-w$ & $\theta-w$ & $\theta-w$ \\
\hline & & 0 & $\theta-w-k$ & $2[\theta-w-s-(1+\rho) k]$ \\
\hline & $\mathrm{F}$ & $2(\theta-w-s)-k$ & $2(\theta-w-s)-(1+\rho) k$ & $2(\theta-w-s)-(1+2 \rho) k$ \\
\hline & & 0 & $\theta-w-(1+\rho) k$ & $2[\theta-w-s-(1+2 \rho) k]$ \\
\hline
\end{tabular}

Table 2. Profits at $t=2$ when A informal at $t=1(\beta=1 ; \rho>0)$

The best responses for each firm can then be obtained. ${ }^{9}$ Putting these responses

\footnotetext{
${ }^{9}$ Suppose $\mathrm{B}$ chooses SO. Then if $0 \leq \theta<w$, A chooses X; if $w \leq \theta<w+2 s+k$, A chooses I; if $w+2 s+k \leq \theta \leq 2 \Theta$, A chooses $\mathrm{F}$.

Suppose B chooses I. Then if $0 \leq \theta<w$, A chooses X; if $w \leq \theta<w+2 s+(1+\rho) k$, A chooses I; if $w+2 s+(1+\rho) k \leq \theta \leq 2 \Theta$, A chooses $\mathrm{F}$.

Suppose B chooses $\mathrm{F}$. Then if $0 \leq \theta<w, \mathrm{~A}$ chooses $\mathrm{X}$; if $w \leq \theta<w+2 s+(1+2 \rho) k$, A
} 
together, it is found that there are two cases, depending on whether $\rho k \gtreqless 2 s$ :

(iii) $\rho k \geq 2 s$. If $0 \leq \theta<w$, we have $\{\mathrm{X}$,SO $\}$. If $w \leq \theta<w+k$, we have $\{\mathrm{I}, \mathrm{SO}\}$. If $w+k \leq \theta<w+2 s+k$, we have $\{\mathrm{I}, \mathrm{I}\}$. If $w+2 s+k \leq \theta<w+(1+\rho) k$, there are two pure-strategy equilibria, $\{\mathrm{I}, \mathrm{I}\}$ and $\{\mathrm{F}, \mathrm{SO}\}$. If $w+(1+\rho) k \leq \theta<w+2 s+(1+\rho) k$, we have $\{$ I,I $\}$. If $w+2 s+(1+\rho) k \leq \theta<w+2 s+(1+3 \rho) k$, we have $\{\mathrm{F}, \mathrm{I}\}$. If $w+2 s+(1+3 \rho) k \leq \theta$, we have $\{\mathrm{F}, \mathrm{F}\}$.

(iv) $\rho k<2 s$. If $0 \leq \theta<w$, we have $\{\mathrm{X}$,SO $\}$. If $w \leq \theta<w+k$, we have $\{\mathrm{I}, \mathrm{SO}\}$. If $w+k \leq \theta<w+2 s+(1+\rho) k$, we have $\{\mathrm{I}, \mathrm{I}\}$. If $w+2 s+(1+\rho) k \leq$ $\theta<w+2 s+(1+3 \rho) k$, we have $\{\mathrm{F}, \mathrm{I}\}$. If $w+2 s+(1+3 \rho) k \leq \theta$, we have $\{\mathrm{F}, \mathrm{F}\}$.

In case (iv), the number of informal firms rises at first with $\theta$, but then falls as formality becomes highly profitable, and in both (iii) and (iv) there is an intermediate value of $\theta$ that gives the pure-strategy equilibrium $\{I, I\}$, as we found for $\rho=0$ and $\beta>1$. However, in case (iii), for $\theta$ in the next higher range, it is found that there are two pure-strategy equilibria, $\{\mathrm{I}, \mathrm{I}\}$ and $\{\mathrm{F}, \mathrm{SO}\}$. For the range of $\theta$ above that we again find a single pure-strategy equilibrium, $\{\mathrm{I}, \mathrm{I}\} .{ }^{10}$

The two pure-strategy equilibria occur when $\rho k \geq 2 s$ and $w+2 s+k \leq \theta<$ $w+(1+\rho) k$. If $\mathrm{B}$ stays out, the lack of pressure on the price of capital makes

chooses I; if $w+2 s+(1+2 \rho) k \leq \theta \leq 2 \Theta$, A chooses Fl.

Suppose A chooses X or I. Then if $0 \leq \theta<w+k$, B chooses SO; if $w+k \leq \theta<w+2 s+(1+2 \rho) k$, B chooses I; if $w+2 s+(1+2 \rho) k \leq \theta \leq 2 \Theta$, B chooses F.

Suppose A chooses F. Then if $0 \leq \theta<w+(1+\rho) k$, B chooses SO; if $w+(1+\rho) k \leq \theta<$ $w+2 s+(1+3 \rho) k$, B chooses I; if $w+2 s+(1+3 \rho) k \leq \theta \leq 2 \Theta$, B chooses $\mathrm{F}$.

${ }^{10}$ If A enters formally at $t=1$ the configurations of firm status that obtain are those in columns 3 and 4 of Table 1 . If A enters informally at $t=1$ then in case (iv) we again have column 4 ; but case (iii) differs from any of the columns in Table 1. 
formality for $\mathrm{A}$, which requires the purchase of additional capital $k$, an attractive proposition; and, since A is buying capital, B does not find it profitable to buy capital at the same time, given that the price will be driven up. This gives the pure-strategy equilibrium $\{\mathrm{F}, \mathrm{SO}\}$. However, if B enters informally, buying capital $k$ to do so, A will not find it profitable to add to its capital stock and become formal because the price of capital will be higher when both firms make a purchase. And given that $\mathrm{A}$ is not purchasing capital, $\mathrm{B}$ finds it profitable to enter, though only informally because $\theta$ is only in an intermediate range. This gives the pure-strategy equilibrium $\{\mathrm{I}, \mathrm{I}\}$.

We assume that when there are two pure-strategy equilibria a mixed-strategy equilibrium obtains. Hence, the outcome may be any of: $\{\mathrm{F}, \mathrm{SO}\},\{\mathrm{I}, \mathrm{I}\},\{\mathrm{I}, \mathrm{SO}\}$ and $\{\mathrm{F}, \mathrm{I}\}$. Consequently, looking at the whole range of $\theta$ values, as demand takes higher values the number of informal firms may rise from 0 to 1 to 2 , but then may fall to 1 or even 0 before, for the two highest ranges of $\theta$, we have 1 and 0 informal firms. Also, since $\{\mathrm{F}, \mathrm{I}\}$ and $\{\mathrm{I}, \mathrm{SO}\}$ are possible outcomes but are not pure-strategy equilibria, 'churning' (turbulence) may be a characteristic of an intermediate realization of $\theta$.

Proposition 2 Suppose that $\beta=1$ and $\rho>0$, and that the leader, firm A, enters informally at $t=1$. Then an intermediate range of realizations $\theta$ of profitability exists for which there are two pure-strategy equilibria at $t=2$. With a mixed- 
strategy equilibrium in this range there may be churning, with no settled behavior with regard to formality and informality.

For both these cases, (iii) and (iv), with firm A entering informally at $t=1$, its expected profit $E \pi_{2 i}^{A}$ at $t=2$ is given by ${ }^{11}$

$$
\begin{aligned}
2 \Theta E \pi_{2}^{A}(i)= & \int_{w}^{w+2 s+(1+\rho) k}(\theta-w) d \theta+\int_{w+2 s+(1+\rho) k}^{w+2 s+(1+3 \rho) k}[2(\theta-w-s)-(1+\rho) k] d \theta \\
& +\int_{w+2 s+(1+3 \rho) k}^{2 \Theta}[2(\theta-w-s)-(1+2 \rho) k] d \theta \\
= & \frac{1}{2}[2 s+(1+\rho) k]^{2}+2 \rho k[2 s+(1+3 \rho) k]+ \\
& 2 \Theta\{2 \Theta-[2(w+s)+(1+2 \rho) k]\}+(w-\rho k)[w+2 s+(1+3 \rho) k] .
\end{aligned}
$$

The first integral covers the range of $\theta$ in which A remains informal. The second and third integrals cover ranges of $\theta$ in which A switches to formality, buying an additional $k$ units of capital. With the second integral B becomes informal, buying $k$ units of capital, the unit price of which is therefore $1+\rho$; with the third integral B becomes formal, buying $2 k$ units of capital, the unit price of capital being $1+2 \rho$. (20) is valid provided

$$
2 \Theta>w+2 s+(1+3 \rho) k
$$

which we assume to hold.

\footnotetext{
${ }^{11}$ To calculate this expected profit we must solve for the mixed-strategy equilibrium that is discussed in the text. Since firm A's profit from remaining informal is independent of B's behavior, this is the expected profit that must obtain for $\mathrm{A}$ in this equilibrium.
} 
Informal entry at $t=1$ earns A a profit stream with an expected present value of

$$
E V^{A}(i)=\Theta-w-k+\sigma E \pi_{2 i}^{A}
$$

\subsection{A's Choice Between Formality and Informality}

Assuming that A enters, it prefers formality (informality) if

$$
E V^{A}(f)-E V^{A}(i)=\Theta-w-2 s-(1+2 \rho) k+\sigma \Delta>(<) 0
$$

where $\Delta=E \pi_{2}^{A}(f)-E \pi_{2}^{A}(i)$. From (19) and (20),

$$
\Delta=(1+2 \rho) k-\frac{1}{2 \Theta}\left\{(2 s+w)(1+2 \rho) k+\left[\frac{1}{2}(1+\rho)^{2}+\rho(1+3 \rho)\right] k^{2}\right\}
$$

Given (22), $\Delta>0$; that is, by entering formally at $t=1$ firm A earns a higher expected profit at $t=2$ than if it entered informally at $t=1$. From (23), a sufficient condition for firm A to prefer formality to informality at $t=1$ is therefore that

$$
\Theta>w+2 s+(1+2 \rho) k
$$

As in Section 3, $d\left[E V^{A}(f)-E V^{A}(i)\right] / d \Theta>0$; that is, a higher $\Theta$ favours formality at $t=1$. Also, $E V^{A}(f)-E V^{A}(i)$ is increasing in $\sigma$, and decreasing in $w, s, k$ and $\rho$. There is a critical value of $\Theta$, which we denote by $\bar{\Theta}$, at which $E V^{A}(f)-E V^{A}(i)=$ 
0. ${ }^{12}$ Firm A prefers formality (informality) at $t=1$ if $\Theta>(<) \bar{\Theta}$.

The comparative statics results are similar to those of the previous section, though now there is an additional parameter $\rho$. If A enters formally at $t=1$ it pays a unit capital cost $1+\rho$ and so its expected profit falls when $\rho$ is raised; but because it then does not expand further, its profitability at $t=2$ is unaffected. If A enters informally at $t=1$ its unit capital cost then is unity, independent of $\rho$. Then, using (21), it can be shown that a higher $\rho$ at $t=2$ reduces A's profitability (although it is discouraging to investment by firm B as well). Also, if A enters informally at $t=1$ a higher value of $\rho$ can make case (iii) rather than (iv) obtain; that is, it results in the possibility of churning.

\subsection{Finance Constraints}

In general, we may expect finance constraints to lead to less investment, but our concern here will be with whether there may be any more interesting effects, particularly on the behavior of the leader, firm A. ${ }^{13}$ We assume that capital investment requires up-front expenditure, which must be financed, but that labor costs do not require such expenditure, being met ex post by sales revenue.

\footnotetext{
${ }^{12}$ Taking the real root of the relevant quadratic, it is found that $\bar{\Theta}=$ $\frac{1}{2}\left\{2[(1-\sigma)(1+2 \rho) k+w+2 s] \pm\left[\{2[(1-\sigma)(1+2 \rho) k+w+2 s]\}^{2}+8 \sigma \Gamma\right]^{1 / 2}\right\}, \quad$ where $\Gamma=\frac{1}{2}(1+\rho)^{2} k^{2}+(2 s+w)(1+2 \rho) k+\rho k(1+3 \rho) k$.

${ }^{13}$ We examine this factor in the present case $(\rho>0, \beta>1)$ rather than in the previous section $(\rho=0, \beta>1)$ because the impact on behavior that concerns us occurs when the profit of each firm depends on the behavior of the other. Such interdependence would also obtain under other assumptions, such as a downward-sloping demand curve for output.
} 
In our model, firm A purchases up to $k$ units of capital at $t=2$, while firm B purchases up to $2 k$ units of capital at $t=2$. Suppose, however, that the amount of finance available at $t=2$ is enough for a total of only $2 k$ units of capital to be bought then. We focus on the case in which it is known with certainty, at $t=1$, that if the constraint binds at $t=2$, it will bind equally, in the sense that at $t=2$ each firm will be able to buy at most $k$ units of capital. Since A will never wish to buy $2 k$ units of capital at $t=2$, this is equivalent to a constraint only on firm B that only $k$ units of capital may be bought.

If $\mathrm{A}$ enters formally at $t=1$ the constraint cannot bind at $t=2$ and so our earlier analysis still holds. If, however, A enters informally at $t=1$ the constraint binds at $t=2$ if both firms want to be formal then. In this case, firm A's choice between exit, continued informality, or a switch to formality will be unaffected; but firm B will be restricted to staying out or informality. Instead of (20), we therefore have

$$
\begin{aligned}
2 \Theta E \pi_{2}^{A}(i)= & \int_{w}^{w+2 s+(1+\rho) k}(\theta-w) d \theta+\int_{w+2 s+(1+\rho) k}^{2 \Theta}[2(\theta-w-s)-(1+\rho) k] d \theta \\
= & \frac{1}{2}[w+2 s+(1+\rho) k]^{2}+\frac{1}{2} w^{2}+ \\
& 2 \Theta\{2 \Theta-[2(w+s)+(1+2 \rho) k]\}
\end{aligned}
$$

If A enters formally at $t=1$ its expected profit at $t=2$ is unaffected by the existence of this constraint. But consider the impact that the constraint has when 
A enters informally at $t=1$. We denote by $\Omega$ the difference between A's expected profit at $t=2$ when the constraint exists and when it does not exist. From (20) and (24),

$$
2 \Theta \Omega=\int_{w+2 s+(1+3 \rho) k}^{2 \Theta} \rho k d \theta=\rho k\{2 \Theta-[w+2 s+(1+3 \rho) k]\} .
$$

Thus, given (21), $\Omega>0$ : the existence of the constraint raises the present value of A's expected profit stream. This is because the constraint prevents B from being formal at $t=2$, limiting the potential competition facing A. Note, however, that this benefit to A only occurs if it enters informally at $t=1$. This gives our third proposition.

Proposition 3 The existence of a common constraint on finance at $t=2$ can encourage entry by the leader, firm $A$, at $t=1$, but it does so by raising the return to informal, rather than formal entry at $t=1$.

For example, the value $\bar{\Theta}$ of $\Theta$ above which formality is preferred is made greater by the existence of the finance constraint. ${ }^{14}$ It may thus occur that in the absence of the finance constraint firm A would enter formally, but with the constraint - which only binds strictly on firm B - firm A chooses to enter informally. Indeed, it may be that in the absence of the finance constraint firm A would not

\footnotetext{
${ }^{14}$ In this case $\bar{\Theta}=[w+2 s+(1-\sigma)(1+\rho) k] / 2+\left\{[w+2 s+(1-\sigma)(1+\rho) k]^{2}+2 \sigma \Phi\right\} / 2$, where $\Phi=(1+\rho) k[w+2 s+(1+\rho) k / 2]$.
} 
enter at all, but with the constraint firm A would enter informally. The formulae underlying these conclusions are quite complicated, but the principle is simple. The constraint restricts the competition that would potentially occur at $t=2$ if, at $t=1$, A entered informally. The expected present value of the profit stream for A resulting from informal entry at $t=1$ is therefore raised, whereas that for formal entry and for staying out are unaffected. The finance constraint can therefore result in informality being a stepping stone.

We could also suppose that there is a finance constraint at $t=1$. There are two forms of this assumption that are consistent with the above analysis. First, it may be that there are $2 k$ units of finance available at $t=1$ but that, since $\mathrm{A}$ is the only firm at this time, it can have all of this finance if it wants it. Secondly, it may be that only $k$ units of finance is available per (potential) firm at $t=1$. This does not affect the interesting part of the story because, in this, informality is chosen at $t=1$. Although with this interpretation we lose the result that the constraint encourages informality (it now forces informality) we still have following result:

Corollary $1 A k$ unit finance constraint on each firm in each period can encourage entrepreneurial entry. 


\section{Conclusions}

We have examined decisions with respect to formality or informality for entrepreneurs in a new industry for a developing economy. By focusing on the decisions $a b$ initio we have been able to deal with issues such as experimentation and strategic behavior that may be critical for both entry and the choice of status. Using a simple framework for tractability, our analysis has enabled us to establish conditions under which different configurations of firm status will occur for the leader and the follower, and we have derived various comparative static results for parameters such as the minimum wage rate and a characterization of ex ante prospects about the profitability of the industry. We have shown that there is not a simple monotonic relationship between the number of informal firms and the realized profitability of the industry.

One of the aims of our analysis was to explore whether the existence of the informal option could boost entry and the long-term development of an industry, including its formal sector. We have shown that informality allows a leader to explore, without significant sunk costs, the potential profitability of the industry; that is, informality may be a stepping stone, enabling an entrepreneur to experiment cheaply in an uncertain environment. We have shown that there are circumstances under which, without this option, the industry would not become 
established. $^{15}$

Informality may alternatively be a consolation prize, that is, it may be the equilibrium status if, once uncertainty has been resolved, the profitability of the industry is relatively low. This is perhaps closer to the traditional view of the sector. However, even in our simple two-firm model there may be multiple equilibria, with churning of entry and status. This can occur when the realized profitability of the industry is at an intermediate level. In this particular case the existence of the informal option creates instability.

Finally, we have also shown that in the entrepreneurial context the existence of finance constraints can actually encourage entry - even if the constraints fall equally on each firm in each period. A constraint can act in a similar way to a patent, limiting subsequent competition by a follower, and thus raising the expected present value of the profit stream for a leader.

\section{References}

[1] Bennett, John, and Saul Estrin, 2006, Regulatory barriers and entry in developing economies, CEDI Working Paper 06-02, Brunel University.

\footnotetext{
${ }^{15}$ Our findings indicate some clear benefits for developing countries from the option of informal status, in contrast to the views of, e.g., Loayza (1994), for whom the informal sector is regarded as a phenomenon likely to constrain economic growth.
} 
[2] Bigsten, Arne, Karl Lundvall and Peter Kimuyu, 2004, What to do with the informal sector? Development Policy Review, 22, 701-715.

[3] Chandra, V., and M.A. Khan, 1993, Foreign investment in the presence of an informal sector, Economica, 60, 79-103.

[4] Fields, Gary S., 2005, A guide to multisector labor market models, World Bank, Social Protection Working Paper No 0505.

[5] Harris, John, and Michael Todaro, 1970, Migration, unemployment, and development: a two sector analysis, American Economic Review, 40, 126-142.

[6] Hausmann, Ricardo, Jason Hwang and Dani Rodrick, 2006, What you export matters, Harvard University, mimeo.

[7] Hausmann, Ricardo, and Dani Rodrick, 2003, Economic development as self discovery, Journal of Development Economics, 72, 603-33.

[8] International Labour Office, 1972, Employment, Incomes, and Equality: a Strategy for Increasing Productive Employment in Kenya. Geneva: ILO.

[9] Lewis, W. Arthur, 1954, Economic development with unlimited supplies of labour, Manchester School, 22, 139-191.

[10] Loayza, N.V., 1994, Labor regulations and the informal economy, Policy Research Working Paper 1335, World Bank, Washington D.C. 
[11] Maloney, 1999, Does informality imply segmentation in urban labor markets? Evidence from sectoral transitions in Mexico, The World Bank Economic Review, 13, 275-302.

[12] Maloney, 2004, Informality revisited, World Development, 32, 1159-1178.

[13] Paula, Aureo de, and Jose Scheinkman, 2006, The informal sector, UCLA Department of Economics working paper.

[14] Rauch, James E., 1991, Modelling the informal sector informally, Journal of Development Economics, 35, 33-47.

[15] Straub, Stéphane, 2005, Informal sector: the credit market channel, Journal of Development Economics, 78, 299-321. 